\title{
A design strategy for improving adaptive conjoint analysis
}

\author{
Ruben Huertas-Garcia \\ Economics and Business Organization Department \\ Barcelona University \\ Spain \\ Juan Carlos Gázquez-Abad \\ Department of Economy and Business \\ University of Almeria \\ Spain \\ Santiago Forgas-Coll \\ Economics and Business Organization Department \\ Barcelona University \\ Spain
}

\begin{abstract}
s
Purpose

Adaptive conjoint analysis (ACA) is a market research methodology for measuring utility in business-tobusiness and customer studies. Based on partial profiles, ACA tailors an experiment's design to each respondent depending on their previously stated preferences, ordered in a self-assessment questionnaire. The aim of this paper is to describe advantages and disadvantages of using a partial-profile randomised experiment, the usual system, and to propose a new design strategy for arranging profiles in blocks that improve its performance.
\end{abstract}

\section{Design/methodology/approach}

We propose a comparison between our design with the commonly used designs, as random designs and the so-called 'mirror image', in their resolution capacity for estimations of main factors and two-factor interactions with the lowest number of profiles.

\section{Findings}

Comparing the proposed design over the other two designs highlights certain aspects. The proposed design guarantees more estimation for each experiment than the others, and allows the researcher tailoring the design to his or her goals. Our procedure will help researchers to determine an experiment's resolution capacity before carrying it out, as well as to estimate main factors and two-factor interactions alike.

\section{Originality/value}

We propose a new design strategy for arranging the profiles in blocks for improving the performance of ACA. Our proposal is based on the use of a full-profile approach in which profiles are arranged in twolevel factorial designs in blocks of two, and the levels of each factor are codified vectorially.

\section{Key words:}

Experimental design strategy, adaptive conjoint analysis (ACA), two-level factorial designs, blocked designs, experiments in $\mathrm{B} 2 \mathrm{~B}$, market research

\section{Article Classification}

Research paper

Published in Journal of Business \& Industrial Marketing, Volume 31, Issue 3 


\section{A design strategy for improving adaptive conjoint analysis}

\section{Introduction}

The use of conjoint analysis (CA) for measuring utility in business-to-business (B2B) marketing research is increasingly common (Stremersch et al., 2003; Wuyts et al., 2009). Although both the concept of utility and its measurement have been studied extensively in marketing literature, some ambiguity remains because of the difficulties involved in observing utility and the absence of an absolute measurement scale (Gustafsson et al., 2007).

CA has the advantage of combining a simple data collection system with a sophisticated design and evaluation methodology. However, despite progress in experimental design and modelling literature, a growing number of studies highlight its inherent limitations, specifically in estimating the partial worth of factors it analyses (Gustafsson et al., 2007). While some deficiencies are attributable to respondent behaviour (McFadden et al., 2005), most are due to the breach of the axioms of the CA model (Louviere et al., 2002). Most empirical CA applications make two basic assumptions, namely that the utility function is an additive polynomial function, and that factors or variables are independent of each other, insofar as between-factor interactions are zero (Teichert and Shehu, 2007). When the principle of independence between factors is not observed, estimating the preference function is much more difficult because of the need to consider possible interactions between attributes, requiring much larger designs as the quantity of profiles grows exponentially (Street et al., 2005). As a result, many empirical applications use fractional factorial designs without testing the independence of the factors under consideration (Hauser and Rao, 2004).

One way to overcome the constraints of $\mathrm{CA}$ is to use sequential experimental methods to improve the efficiency of designs and alleviate the problem of considering that the interaction factors must be zero. Nowadays, sequential experimental models are particularly relevant because, with the advent of online market research, conjoint experiments can be developed by computer, programmed sequentially, and performed in real time (Huertas-Garcia et al, 2013). Indeed, a computerized data collection has enabled researchers to develop adaptive questionnaires that maximize the amount of information collected in each question (Netzer and Srinivasan, 2011). The literature presents several ways of approaching sequential research. One of the first was the adaptive conjoint analysis (ACA) described by Johnson (1987), who suggested combining different types of methodologies in a single piece of research (e.g. a selfassessment questionnaire to identify main factors, and an experimental design to estimate their part-worth).

ACA is a hybrid experiment that combines two methodologies in two steps. In the first step, each interviewee evaluates a long list of attributes using a self-assessment questionnaire (a composition methodology). In the second step, the most preferred attributes are combined in partial profiles and shown to individuals in blocks of two randomly arranged profiles (a decomposition methodology) (Johnson and Orme, 1996). While the first step has been widely discussed in the literature (Scholz et al., 2010; Netzer and Srinivasan, 2011), the second step has attracted much less interest, with most of the focus centring on building subsets or blocks in general (Zeithammer and Lenk, 2009). Indeed, using a subset of profiles and a partial-profile approach for data collection is one of the most salient features of the second stage of ACA. This method involves each interviewee assessing different scenarios (presented step by step) that consist of a few profiles (a subset of the full profile) in which each concept comprises a combination of levels for certain factors (but not all) under analysis. Subsequent literature shows that it is possible to achieve efficient results using blocks of partial-profile designs (Kuhfeld et al., 1994). However, there is much debate about how to choose subsets from a full factorial design, and the use of a partial-profile approach.

With regard to the former issue, there are different ways of grouping profiles into subsets: (1) manually; (2) by means of computer optimisation algorithms; and (3) by means of randomised selection by computer (Chrzan and Orme, 2000). Each method has its pros and cons, and should thus be used on the basis of careful consideration rather than arbitrarily. With regard to the 
second issue, a significant volume of literature finds that a partial profile offers more statistical and behavioural advantages than a full profile. However, a full profile measures overall judgments based on a more realistic description of stimuli and can make direct use of typical behaviour-oriented constructs, such as purchase intent, likelihood of choice, likelihood of shifting to a new brand, and so on (Green and Srinivasan, 1990; Hauser and Rao, 2004; Gazley et al., 2011).

In this study, we propose a new design strategy for improving the performance of the second step of the ACA process. We follow the suggestion made by Kuhfeld et al. (1994) that using both human design skills and a computerised search constitutes the best strategy for design experiments. In particular, we propose a way of arranging profiles manually into subsets of two profiles, which could be automated by a computer algorithm, using a full-profile approach to show the prototypes. Using our procedure, researchers can determine the resolution capacity of an experimental design before applying it. In addition, it makes it possible to estimate main factors and two-factor interactions alike. We provide an example using four two-level main factors supports to endorse our proposed design, and offer practical evidence in support of its use in $\mathrm{B} 2 \mathrm{~B}$ marketing research.

\section{Adaptive conjoint analysis}

ACA was proposed by Johnson (1987) as a solution for estimating preferences over a large number of attributes, and has been developed by Sawtooth Software. Today, it is a computerassisted process for gathering customer assessments of different profiles of new or improved products. The adaptive sequential experiment process can only be achieved thanks to its associated software, rendering it unsuitable for any type of non-interactive configuration (e.g. written questionnaires). Owing to its ability to adapt a high number of attributes in simple choice tasks, ACA has become one of the most frequently used processes for studying customer preferences, after discrete-choice models (Toubia et al., 2007). Additionally, its predictive capacity has been shown to be similar to that of traditional CA, and it can thus be considered an appropriate alternative when dealing with a very high number of attributes.

As described above, ACA combines two methodologies in two steps. The first step likewise includes two data collection stages: first, choosing the most preferred attribute levels, using a 010 rating, and, second, assessing the relative attribute importance, distributing 100 points between them. On completion of this first phase, the most preferred attributes and levels for use in the second step are known (Scholz et al., 2010; Netzer and Srinivasan, 2011).

In the second step, the most preferred attributes are combined in partial profiles and shown to individuals in blocks of two randomly arranged profiles (a decomposition methodology) (Johnson and Orme, 1996). Although each interviewee assesses a set of only a few profiles, every profile will have been evaluated by a percentage of interviewees by the end of the experiment. This two-step process is applied when studying a high number of attributes and so many factors that it is impossible to design an experiment because of the large quantity of profiles that such a design would generate.

This methodology was refined by Toubia et al. (2003), who developed a polyhedral model to improve the sequence of questions, which is adapted to each interviewee. Their proposition enables information to be gathered as efficiently as possible, bearing in mind that the model is primarily used in online surveys, which participants are free to abandon at any time (Hauser et al. 2010).

\subsection{Issues related to two-profile blocks}

The arrangement of profiles in blocks involves taking groups or subsets of profiles, with a smaller size than that of the full profile set, and asking respondents to evaluate them rather than having them asses the whole choice set. The arrangement in blocks generates more relevant statistical information, while improving the variance and covariance of estimates, because of restrictions that involve the exclusion of some alternatives. Using randomly arranged two- 
profile subsets gives ACA many advantages, both in terms of respondent behaviour and statistically speaking. In the case of the former, smaller choice sets make it easier and faster for respondents to perform assessments, so they can repeat the task several times. They can also provide researchers with more data for improving estimations, while keeping both time and perceived difficulty constant. The pairwise comparison of profiles is the easiest way to evaluate respondents' preferences, given that as the number of attributes included in each profile increases the number of comparisons to be performed by subjects in their evaluation task is multiplied (Scholz et al., 2010).

One of the statistical benefits of two-profile blocks is that both the variance and covariance of estimations are improved as a consequence of choice-set exclusion restrictions imposed by small-set arrangements. When a certain option is excluded from a choice set, the probability of it being chosen disappears, permitting better estimations of the remaining parameters (Zeithammer and Lenk, 2009). Another statistical advantage is the automatic balancing that occurs when a small number of profiles are arranged in subsets and randomly presented to respondents. Such automatic balancing is necessary when a choice set features a relatively dominant profile and respondents rarely choose the others. Experiments organised in blocks can help to improve estimates for factors corresponding to the less attractive options (Zeithammer and Lenk, 2009).

However, if a researcher's goal is to estimate not only main factors but also two-factor interactions, there is no guarantee of random profile assignment generating a design with an adequate resolution capacity. That can only be assured by using a statistical design manually or a computerised optimisation algorithm.

\subsection{Issues related to the full and partial-profile format}

ACA as a variety of randomly composite designs is characterised by the use of partial profile stimuli (Johnson 1987); however, in the approach adopted here, in the proposed experimental design, we use full profile stimuli. Each type of stimulus has statistical and cognitive advantages and drawbacks; yet, the full profile has the advantage of making the experiment more realistic.

As pointed out above, two kinds of design format are featured in the literature, namely the fullprofile and partial-profile formats (Wittink et al., 1994). In the case of the former, each profile has a combination of levels for all the factors or variables involved in an experiment. In the case of the latter, contrastingly, only a few factors are involved in profile design.

Recently, the literature has pointed out some advantages of using partial as opposed to full profiles, stemming from the cognitive difficulty of assessing choice sets in which profiles are arranged on the basis of variations in factors as opposed to variations in levels. The level-based arrangement is known as 'alignable assortment', and the factor-based arrangement as 'nonalignable assortment' (Som and Lee, 2012), with a greater degree of difficulty being involved in undertaking an assessment and making a choice within a non-alignable assortment. Specifically, many more mental steps are required when comparing two different attributes or factors within a choice set (e.g. a car's engine power and its interior styling) than when comparing two levels corresponding to the same attribute (e.g. a 1.3-litre engine and a 2.2-litre engine) (Gourville and Soman, 2005). Furthermore, the larger a choice set is, the more difficult it becomes to choose from a non-alignable assortment than from an alignable assortment (Som and Lee, 2012).

The literature has also highlighted the statistical advantages of partial-profile designs. Firstly, experiments using partial profiles are considered to improve identification and parameter estimation in comparison to full-profile models. Additionally, in terms of variance and covariance analysis, excluding certain choice-set attributes can help to improve assessment of the rest (Zeithammer and Lenk, 2009). The explanation for this is highly intuitive. Consider an experiment including three attributes, one of which (e.g. a brand) is very prominent (Eckert et al., 2012). In a full-profile evaluation that compares products including the three attributes in a choice model, there will be a tendency to overestimate the dominant attribute in relation to the 
other two. However, with a partial-profile (e.g. two-by-two) model, in some situations comparisons will be made between the two less prominent attributes, offering a greater balance in results and, consequently, enhancing estimates corresponding to less relevant attributes (Kuhfeld et al., 1994).

In short, partial profiles have cognitive and statistical advantages over full-profile designs. However, full-profile arrangements have frequently been used in the literature (Hauser and Rao, 2004). The main argument supporting the full-profile approach is that all factors or attributes are presented to respondents for their evaluation, providing more realistic descriptions of stimuli than those provided by the partial-profile model. In other words, it simulates consumers' everyday choice processes more accurately, helping to reduce the artificiality of experiments (Wells, 1993). Moreover, the arguments presented in support of the benefits of the partialprofile model are essentially cognitive and rational. Besides, the literature increasingly considers emotional factors (both symbolic and unconscious) as relevant in the choice and purchase process (Elliott and Wattanasuwan, 1998), and these can be picked up much better with full-profile designs. But, due to information saturation problems, the full-profile procedure is typically restricted to five or six factors. Nevertheless, for a limited number of factors and an environment in which correlation is important, the full profile is usually better in terms of predictive validity (Green and Srinivasan, 1990).

This study proposes a methodology for manually building a statistical design of full-profile stimuli comprising two-profile sets. The aim of this design is to estimate main factors and twofactor interactions in a quadratic equation with the lowest number of profiles. The design is based on studies by Yang and Draper (2003) of two-level factorial designs in blocks of size two. The method in question has two additional advantages for market researchers. Firstly, it makes it possible to build profile blocks adapted to a researcher's needs and of greater relevance in terms of estimating a part-worth's main factors or two-factor interactions, with no confounding. Secondly, it allows, through the introduction of a block effect variable, for variability to be generated. In other words, this variable captures the fact that in a conjoint experiment different groups of people evaluate different blocks containing different profiles, while in a discretechoice experiment it captures the learning process that each subject is involved in when assessing different profile blocks. However, this block variable involves certain theoretical assumptions, namely, that the block variable effect is additive, generating changes in the dependent variable only, and that there are no block-factor interactions (Yang and Draper, 2003).

However, the new methodology presented in this paper also involves some initial restrictions. This study has been developed on the basis of an individual conjoint analysis, as proposed in ACA, encompassing up to four factors. Our procedure is thus an attributes-only model (Raghavarao et al., 2011). In particular, our analysis has focused on the estimation of main factors and two-factor interactions, ignoring other aspects, such as so-called 'availability cross effects' (Lazari and Anderson, 1994).

\section{Features of the proposed design}

The second step of an ACA process involves the generation of two-profile choice subsets. Sawtooth Software uses different types of random designs to form choice sets:

1) Complete enumeration. This system generates a full factorial. It assigns subsets to respondents with a view to achieving a balance between attributes and levels, as well as to minimising duplication (or overlap).

2) Shortcut. A subset arrangement criterion is used to choose attributes not present in the previous arrangement.

3) Random choice. A random design criterion, with replacement, is used for forming subsets. Overlap is permitted, but a choice set may not feature two identical profiles. 
4) Hybrid designs. Choice sets are formed by combining two of the above strategies (Chrzan and Orme, 2000).

Depending on experiment type (e.g. brands-only, attributes-only or brands-with-attributes; see Raghavarao et al., 2011) and design type (including more or less overlap), it is possible to measure main or higher-order effects. In this paper, we focus on measuring main effects and two-factor interactions, considering that three and higher interaction effects are zero.

We propose the use of blocks to arrange profiles in choice sets. Blocks are defined as instruments intended to reduce the variability that a range of circumstances (e.g. time interval between experiments, setting or personnel-related considerations, etc.) cause where respondents' answers are concerned (Rosenbaum, 1999). The use of blocks involves certain theoretical principles. Firstly, block effects are additive, generating change only in the dependent variable. Secondly, there is no block-factor interaction (Yang and Draper, 2003).

The most commonly used designs are random designs (Zeithammer and Lenk, 2009) and the socalled 'mirror image' (or foldover), a type of shortcut design (Box et al., 2005; Raghavarao et al., 2011). Both approaches have certain limitations. Firstly, a randomly arranged choice set does not guarantee an adequate resolution capacity for estimating main factors and two-factor interactions. Secondly, only main factors can be estimated with the foldover design. The resolution capacity is related to the correlation established between main factors, or between main factors and second-order interactions, or between two-factor interactions. Although the statistical design of experiments is orthogonal, this requires such a large number of profiles that, quasi-orthogonal designs are used in empirical studies. In the random assignment of profiles, the researcher rapidly loses control of the design and, although the software usually ensures a low correlation between main factors, it is much more difficult to control two-factor interactions.

Table 1 shows an example of four factors arranged randomly, with replacement, in blocks of two, and the corresponding resolution capacity. Identifying the resolution capacity of a design is very simple. To estimate the effect of one factor in a block, it must contain two opposing signs in the two profiles, otherwise such estimation is impossible. For instance, Table 1 shows randomly-paired arrangements in blocks of two profiles, with block 1 being formed by profiles 10 and 12. In this block, it is possible to estimate the main effect $\mathrm{B}$ and the two-factor interactions $\mathrm{AB}, \mathrm{BC}$ and $\mathrm{BD}$, but not the main factors $\mathrm{A}, \mathrm{C}$ or $\mathrm{D}$, nor the other two-factor interactions. This means that once a respondent has evaluated eight two-profile scenarios, the researcher will have five estimations of factor $\mathrm{A}$, seven of factor $\mathrm{B}$, three of factor $\mathrm{C}$, three of factor $\mathrm{D}$, and so on.

Table 2 shows an example of a foldover arrangement in blocks of two. This array is a type of shortcut design built using two profiles, in which the first profile's factor levels are completely reversed in the second. Only main factors can be estimated with this strategy, as all the twofactor interactions are confounded (Yang and Draper, 2003). Moreover, when there is already an initial arrangement, it is very difficult to find other pairs of block designs to complement the experiment in order to estimate two-factor interactions (Rosenbaum, 1999).

\section{Insert Table 1}

\section{Insert Table 2}

We therefore need alternative blocking methods that allow for the estimation of main factors and two-factor interactions. Box et al. (2005) suggested different experimental designs that sequentially confound the different main factors and interactions but, overall, can generate reasonably efficient estimations. As Yates (1970) noted, confounded effects are not lost; they are simply effects with a higher variance than the others. That idea was taken up by Draper and Guttman (1997), who proposed a new way to arrange blocks of size two. In this paper, we adapt 
those ideas to ACA in order to improve its performance and to estimate main factors and twofactor interactions with the lowest number of profiles.

\title{
4. An example of the proposed procedure
}

The following example illustrates our proposed procedure. Wuyts et al. (2009) studied factors affecting the selection of a service provider in a B2B market, focusing in particular on a market research agency. Their results suggested that the most important factors were 'Attention to the interpretation of data and advice', 'Personal relationship with employees of the agency', 'Reputation for expertise in the type of research involved' and 'Recommendations from other clients'. We refer to these factors as A, B, C and D, respectively. Each of them has two vectorially codified levels (for factor $\mathrm{A}, 1=$ much attention and $-1=$ less attention; for factor $\mathrm{B}$, $1=\operatorname{good}$ and $-1=$ none; for factor $\mathrm{C}, 1=$ much expertise and $-1=$ less expertise; and for factor $\mathrm{D}, 1=$ recommended and $-1=$ not recommended). A full-factorial design comprises 16 profiles $\left(2^{4}=16\right)$. Arranging this experiment in blocks of size two, we have:

$$
C_{2}^{16}=\frac{16(16-1)}{2}=120 \text { pairs of profiles }
$$

To divide a full factorial into blocks, block generators are required. A block generator is a variable (usually a high-level interaction) that is used to separate profiles into blocks and, therefore, its value can be confused with that of the separation of profiles in blocks. In line with usual procedures, we calculate the value of the high-level interaction and separate profiles presenting the same values. In our example, each block generator requests three block variables (named B1, B2 and B3) (for more information on block generators, see Box et al., 2005). Draper and Guttman (1997) showed that for $k$ factors there are $2^{k}-1$ ways of arranging block generators of size two, and each can be classified on the basis of the use of one of two factor interactions as a block variable. In our example, featuring four factors, there are 15 ways of arranging the block generators, and they can be classified into four categories, specifically type 1, with main factors only as block variables; type 2 , with one two-factor interaction and main factors in the other cases; type 3, with two two-factor interactions; and type 4, with three two-factor interactions (Table 3 shows the 15 arrangements classified into these four categories). Each arrangement consists of 16 profiles in eight blocks of two. This classification is systematic, insofar as all possible ways of arranging a full factorial in blocks of two are considered, and it also indicates the resolution capacity corresponding to main factors and two-factor interactions in each design.

\section{Insert Table 3}

Once the researcher has classified all possibilities, that is, manually adapted them in line with his or her specific interest. Each researcher chooses the combination best suited to their objectives. For example, if a researcher is seeking the most information possible on main effects, the most appropriate design is the four-block type with only one arrangement (i.e. \#15, the foldover design shown in Table 2). In our case, we selected those offering the best resolution for main factors but with enough information to estimate all two-factor interactions, meaning a three-block design. To fulfil both objectives we had to choose three block arrangements from the four options available (choosing only two prevents the estimation of one of the two-factor interactions). The three we chose were number 11, with the block variables A, $\mathrm{BD}$ and $\mathrm{CD}$; number 12, with $\mathrm{B}, \mathrm{AD}$ and $\mathrm{CD}$; and number 13, with $\mathrm{C}, \mathrm{AD}$ and $\mathrm{BD}$. Tables 4,5 and 6 show the three designs in question.

\author{
Insert Table 4 \\ Insert Table 5 \\ Insert Table 6
}




\section{Insert Table 7}

Table 7 shows the resolution level of each of the chosen arrangements and the corresponding sum. Using these three arrangements, it is possible to obtain 16 estimations for three main factors, A, B and C; 24 estimations for the main factor D; 16 estimations for the interactions $\mathrm{AB}, \mathrm{AC}$ and $\mathrm{BC}$; and eight estimations for the interactions $\mathrm{AD}, \mathrm{BD}$ and $\mathrm{CD}$. Consequently, every respondent must evaluate 24 two-profile scenarios to provide enough information to estimate all the main factors and two-factor interactions.

Comparing this experimental design's resolution capacity to that of the other two designs highlights certain aspects. While this arrangement guarantees eight estimations for six factors from the 10 variables in each design, the foldover design provides just eight estimations for the four main effects only. The random model generates estimations for the 10 variables but without following any pattern and, in this case, without reaching eight estimations per variable. The random design forces the researcher to leave block formation to chance, resulting in the loss of the initiative involved in previously determining the resolution capacity they want each variable type (main factor or two-factor interaction) to have.

In summary, the arrangement selection process consists of: (1) establishing the resolution level of each of the 15 block arrangements and classifying them into categories (see Table 3); (2) combining the resolution of each block arrangement, two by two and then three by three, depending on the research objective; and (3) determining the resolution capacity of each experimental design before application.

A final question that arises is whether evaluating 24 pairs of profiles places an excessive burden on respondents in a computer-aided experiment. In a study conducted by Sawtooth Software, in which discrete-choice models were applied, it was shown that, within the 10-20 task range, doubling the number of tasks per respondent is more effective than increasing precision with twice the number of respondents (Johnson and Orme, 1996). A 24-choice task is therefore acceptable and within the limits of respondents' capacity.

\section{Conclusions and limitations}

Disciplines that publish tutorial papers on 'how to' design experiments have been witnesses to a proliferation of empirical studies (Flynn 2010). In this context, the aim of this study has been to propose a new design strategy for improving the performance of the second step in the ACA process. Accordingly, our results show that manually arranging two-level factorials in blocks of two, as has been proposed in this study, has the same statistical and behavioural advantages as arranging blocks randomly. Firstly, forming two-profile blocks as choice sets makes assessment faster and easier for respondents, who can therefore repeat tasks many times without growing tired of doing so. Secondly, it also has advantages in terms of the variance and covariance estimates, due to exclusion restrictions. Finally our proposed design guarantees automatic balancing if a choice set has a dominant profile.

Although in recent years, the use of partial profile prototypes in conjoint analysis has gained in popularity, thanks to their cognitive (Som and Lee, 2012) and statistical (Zeithammer and Lenk, 2009) advantages, academics and professionals remain sceptical about the ability of these methods to estimate a stable factor's part-worth at the individual level for products or services that have a large number of attributes, even when using a hierarchical Bayes approach (Netzer and Srinivasan, 2011). By way of an alternative, we propose using the full-profile approach for presenting attributes and level combinations to respondents when gathering information, a proposal that has been validated by the literature on CA, market research and customer behaviour, and which can be adapted to models of choice-based CA. Profiles arranged in such a manner provide more realistic descriptions (similar to those used in everyday life) and greater predictive validity (Green and Srinivasan, 1990). 
Our proposed design has been illustrated in this paper with an example of how it could be adapted to B2B marketing research. As Louviere et al. (2013) stress, a tutorial document should benefit academics and marketing professionals and, certainly, this has been the primary goal of this paper. Specifically, we believe that our proposal for using a statistical experimental design for arranging blocks of two profiles allows researchers and professionals to maintain their control over the results, insofar as they can decide, in line with their pre-established objectives, the block generator type that best suits their needs. For example, if they consider that two-factor interactions are meaningless in relation to the first main factor, A, they can choose a block generator type 2, as illustrated by designs 8,9 and 10 from Table 3 . By contrast, if profiles are assigned randomly, researchers and practitioners are slaves to the design generated when analysing the data.

Establishing the number of profiles to be assessed by respondents in a sequential experiment is important in terms of determining viability for market research purposes (Huertas-Garcia et al. 2013). As indicated above, we have presented an example designed for a B2B framework, featuring four factors and requiring 24 assessments to obtain sufficient information to fit a linear model with main factors and two-factor interactions. Four factors were selected here for two reasons: first, according to Johnson and Orme (1996), this is the average number of factors obtained after the first stage of ACA; and, second, because it is the maximum number of factors that can be analysed at the individual level since it generates a number of tasks that lie within the usual limits. For example, were we to have considered five factors, the design would have required three arrangements of 16 size-two blocks, giving a total of 48 blocks with 96 profiles. Clearly, evaluating 48 scenarios is too much to expect from respondents in any computer-aided experiment.

We have made some basic assumptions in this paper, as our interest is limited to an attributesonly model and the estimation of main factors and two-factor interactions. Other designs (e.g. brands-only or brands-with-attributes) and aspects (e.g. availability cross effects) have not been considered. Regarding block design, we have worked on the basis of block effects being additive and of there being no block-factor interaction. However, the model can be used in any type of experiment in which the dependent variable may be a mean, a proportion, etc., providing scope for discrete-choice models (Halme and Kallio, 2011) and enough flexibility to adapt to each researcher's requirements. In order to apply such arrangements in ACA methodology though, independent variables should be of the two-level type, to enable the researcher to form an acceptable number of two-profile combinations, so as not to exceed respondents' capacity.

This study is still preliminary in nature and has a number of limitations. Firstly, the design used in our example is very simple, involving only four factors at two levels. While it is standard practice to use four factors in the second step of ACA, CA commonly uses six or seven (Wittink and Cattin, 1989). Secondly, ACA allows for different forms of application, from individual to aggregate analyses, entailing different ways of approaching the results. This paper has focused specifically on an individual analysis (i.e. with each respondent assessing all the scenarios); however, were we to have considered a higher number of attributes, the analysis would have been aggregate in nature. Many authors have criticised the use of individual analyses, especially for forming segments. For instance, Elrod et al. (1992) pointed out the instability and bias in individual-level part-worth estimates, and Kamakura et al. (1994) reported that two-stage procedures tend to ignore the estimation error associated with part-worth estimates from the first stage of ACA. All those considerations result in poor adjustment in models at individual level.

Aggregate analysis overcomes some of the restrictions that individual analysis involves. Firstly, it allows for the use of a larger number of factors without placing an excessive burden on respondents, as each respondent is only required to assess one block arrangement, with the researcher performing an aggregate analysis encompassing all respondents at the end of their experiment. Secondly, the aggregate level makes it possible to compile a number of answers from each block, thus enabling the researcher to provide a better model fit. One disadvantage is the incorporation of a heterogeneous group of people into the aggregation process. This type of analysis requires the use of groups deemed homogeneous a priori, based on their observable 
characteristics (e.g. socio-demographics), with consumers' preferences then being estimated on an aggregate basis by segment. A further disadvantage of an aggregate analysis is that while experimental designs are efficient at this level, they are not efficient for each individual (Yu et al., 2011). In other words, if we consider our design proposal in an aggregate approach, in which each individual evaluates just one block. As such a block, the assessment would be partial; yet, in order to undertake a global assessment of all the alternatives would require three individuals.

The success of this approach depends on the strength of the relationship between sociodemographic characteristics and consumer preferences. With a weak relationship, the approach would generate spurious factor estimations, as documented by Elrod et al. (1992). A series of latent class-segmentation analyses have been proposed (e.g. Kamakura et al., 1994) with a view to overcoming the limitations caused by the assumption of preference homogeneity across consumers. However, the consequences of using partial designs individually in an aggregate analysis remain unclear.

We are currently planning future experiments using computer-aided sequential approaches to empirically assess the internal and external validity of our proposed method. However, must be taken into account if the number of factors is from two to four, individual analysis will be possible; or if the number is higher, the analyses would have to be aggregate. Both types of analyses have their strengths and weaknesses, as detailed in this study, and as such more research is required to identify methods to overcome the main drawbacks.

\section{Bibliography}

Box, G. E. P., Hunter, J. S. and Hunter, W. G. (2005), Statistics for experimenters: Design, innovation, and discovery (2nd ed.), Wiley, Hoboken.

Chrzan, K. and Orme, B. (2000), "An overview and comparison of design strategies for choicebased conjoint analysis", Sawtooth Software Research Paper. Sawtooth Software, Inc. Orem, UT, EEUU.

Draper, N. R. and Guttman, I. (1997), "Two-Level Factorial and Fractional Factorial Designs in Blocks of Size Two", Journal of Quality Technology, Vol.29, pp. 71-75.

Eckert, C., Louviere, J. J. and Islam, T. (2012), "Seeing the forest despite the trees: Brand effects on choice uncertainty", International Journal of Research in Marketing, Vol.29, No 3, pp. 256-264.

Elliott, R. and Wattanasuwan, K. (1998), "Brands as symbolic resources for the construction of identity", International Journal of Advertising, Vol. 17, pp. 131-144.

Elrod, T., Louviere, J. J. and Davey, K. S. (1992), "An empirical comparison of ratings based and choice based models", Journal of Marketing Research, Vol.29, No.3, pp.368-377.

Flynn, T. N. (2010). "Valuing citizen and patient preferences in health: Recent developments in three types of best-worst scaling". Expert Review of Pharmacoeconomics \& Outcomes Research, Vol. 10, No. 3, pp. 259-267.

Gazley, A., Clark, G. and Sinha, A. (2011), "Understanding preferences for motion pictures", Journal of Business Research, Vol. 64, pp. 854-861.

Gourville, J. T. and Soman, D. (2005), "Overchoice and Assortment Type: When and Why Variety Backfires", Marketing Science, Vol.24, No.3, pp. 382-395 
Green, P. E. and Srinivasan, V. (1990), "Conjoint analysis in marketing research: New developments and directions", Journal of Marketing, Vol.54, No.4, pp. 3-19.

Gustafsson, A., Herrmann, A. and Huber, F. (2007), Conjoint measurement: Methods and applications (4th ed.), Springer, Berlin.

Halme, M. and Kallio, M. (2011), " Estimation methods for choice-based conjoint analysis of consumer preferences", European Journal of Operational Research, Vol. 214, pp. 160-167.

Hauser, J. and Rao, V. (2004), "Conjoint Analysis, Related Modelling and Applications", in: Wind, Y. and Green, P. (Eds.), Marketing Research and Modeling, Progress and Prospects, A Tribute to Paul Green, Springer, Dordrecht, pp.141-168.

Hauser, J. R., Toubia, O., Evgeniou, T., Befurt, R. and Dzyabura, D. (2010), "Disjunctions of conjunctions, cognitive simplicity, and consideration sets", Journal of Marketing Research, Vol. 47, No 3, pp. 485-496.

Huertas-Garcia, R., Gázquez-Abad, J.C.; Martínez-López, F. J. and Esteban-Millat, I. (2013), "Using response surface methodology to optimise factors in conjoint experiments", International Journal of Market Research, Vol. 55, No 2, pp.267-288.

Johnson, R. M. (1987), "Accuracy of Utility Estimation in ACA", Working Paper. Sawtooth Software. Sawtooth Software, Inc. 1987

Johnson, R. M. and Orme, B. K. (1996), " How Many Questions Should You Ask in ChoiceBased Conjoint Studies?", Sawtooth Software. Research Paper Series, Sawtooth Software, Inc. 1996

Kamakura, W. A., Wedel, M. and Agrawal, J. (1994), "Concomitant variable latent class models for conjoint analysis", International Journal of Research in Marketing, Vol.11, No.5, pp. 451-464.

Kuhfeld, W. F., Tobias, R. D. and Garratt, M. (1994), "Efficient Experimental Design with Marketing Applications", Journal of Marketing Research, Vol.31, No.4, pp. 545-557.

Lazari, A.G. and Anderson, D. A. (1994), "Designs of Discrete Choice Set Experiments for Estimating Both Attribute and Availability Cross Effects", Journal of Marketing Research, Vol.31, No.3, pp. 375-383

Louviere, J. L.; Ling, I.; Islam, T.; Gudergan, S. and Flynn, T. (2013). "An introduction to the application of (case 1) best-worst scaling in marketing research", International Journal of Research in Marketing, Vol. 30, No. 3, pp. 292-303.

Louviere, J., Street, D., Carson, R., Ainslie, A., Deshazo, J., Cameron, T., Hensher, D., Kohn, R. and Marley, T. (2002), "Dissecting the Random component of Utility", Marketing Letters, Vol.13, No.3, pp.177-193.

Mc Fadden, D.L., Bemmaor, A. C., Caro, F. G., Dominitz, J., Jun, B-H., Lewbel, A., Matzkin, R. L., Molinari, F., Schwarz, N., Willis, R. J. and Winter, J.K. (2005), "Statistical Analysis of Choice Experiments and Surveys", Marketing Letters, Vol.16, No.3/4, pp.183-196.

Netzer, O. and Srinivasan, V. (2011), "Adaptive Self-Explication of Multiattribute Preferences", Journal of Marketing Research, Vol. 48 (February), pp. 140 -156. 
Raghavarao, D., Wiley, J. B. and Chitturi, P. (2011), Choice-based conjoint analysis: Models and designs (1 edition ed.), Chapman and Hall/CRC, Boca Raton.

Rosenbaum, P. R. (1999), "Blocking in Compound Dispersion Experiments", Technometrics, Vol.41, No.2, pp. 125-134

Scholz, S. W., Meissner, M. and Decker, R. (2010), "Measuring consumer preferences for complex products: a compositional approach based on paired comparisons", Journal of Marketing Research, Vol. 47, No 4, pp. 685-698.

Som, A. and Lee, Y. H. (2012), "The joint effects of choice assortment and regulatory focus on choice behavior", International Journal of Research in Marketing, Vol.29, No.2, pp. 202209.

Street, D., Burguess, L. and Louviere, J. (2005), "Quick and Easy Choice Sets, Constructing Optimal and Nearly Optimal Stated Choice Experiments", International Journal of Research in Marketing, Vol.22, No.4, pp. 459-470.

Stremersch, S., Weiss, A. M., Dellaert, B. G. C. and Frambach, R. T. (2003), "Buying Modular Systems in Technology-Intensive Markets", Journal of Marketing Research, Vol.40, No.3, pp. 335-350.

Teichert, T. and Shehu, E. (2007), "Evolutionari Conjoint", in Gustafsson, A., Herrmann, A. and Huber, F. (Eds.) Conjoint Measurement. Methods and Applications ( $4^{\text {th }}$ Edition), Springer, Berlin, pp. 113-132.

Toubia, O., Simester, D. I., Hauser, J. R. and Dahan, E. (2003), "Fast Polyhedral Adaptive Conjoint Estimation", Marketing Science, Vol.22, No.3, pp. 273-303.

Toubia, O., Evgeniou, T. and Hauser, J. R. (2007), "Optimization-Based and Machine-Learning Methods for Conjoint Analysis: Estimation and Question Design", in Gustafsson, A., Herrmann, A. and Huber, F. (Eds.), Conjoint Measurement. Methods and Applications (4th Edition), Springer, Berlin, pp. 231-258.

Wells, W. D. (1993), "Discovery-Oriented Consumer Research", Journal of Consumer Research, Vol. 19, No. 4, pp. 489-504

Wittink, D. R. and Cattin, P. (1989), "Commercial use of conjoint analysis: An update", Journal of Marketing, Vol.53, pp. 91-96.

Wittink, R. D., Vriens, M. and Burhenne, W. (1994), "Commercial use of conjoint analysis in Europe: Results and critical reflections", International Journal of Research in Marketing, Vol.11, No. 1, pp. 41-52

Wuyts, S., Verhoef, P. C. and Prins, R. (2009), "Partner selection in B2B information service markets", International Journal of Research in Marketing, Vol.26, No.1, pp. 41-51.

Yang, Y. J. and Draper, N. R. (2003), "Two-Level Factorial and Fractional Factorial Designs in Blocks of Size Two", Journal of Quality Technology, Vol.35, No.3, pp. 71-75.

Yates, F. (1970), Experimental design; selected papers of Frank Yates, Griffin, London. 
Yu, J., Goos, P. and Vandebroek, M. (2011), "Individually adapted sequential Bayesian conjoint-choice designs in the presence of consumer heterogeneity", International Journal of Research in Marketing, Vol. 28, No 4, pp. 378-388.

Zeithammer, R. and Lenk, P. (2009), "Statistical benefits of choices from subsets", Journal of Marketing Research, Vol.46, No.4, pp.816-831.

\section{APPENDIX: EMPIRICAL APPLICATION OF PROPOSED METHOD*}

In order to illustrate our method, we develop an experiment involving the design of store flyers. In this case, we focus our analysis at the aggregate level, so that each sample of individuals assesses just one block in the experimental design.

The objective is to determine how the design of store flyers influences customers' store-related decisions (i.e., their intention to visit the store and to purchase items). Specifically, the design elements under study are the following: (1) brand type (national vs. store's own brandhenceforth SB) on offer; (2) brand type (national vs. SB) featured on the cover of the store's flyer; (3) \# of national brands featured together with the SBs; (4) price range considering the most expensive national brand and the cheapest SB, and (5) the size of the store flyer. In order to determine how these design elements influence consumers' decisions, a conjoint study combined with a between-subject experiment was conducted via Internet.

The factors (and levels) identified in the above process and encoded in a pattern vector were:

(1) \# of national brands featured on the private label $(1=$ three national brands, $-1=$ one national brand),

(2) brand being promoted $(-1=\mathrm{SB}, 1=$ national brand),

(3) difference between the highest (national brand) price and the lowest SD price (-1 = less than $20 \%, 1=$ more than $20 \%$ ).

Based on real exposure settings in Spain, each page presented a specific product theme. The yogurt brands appeared among the snacks and pastries, whereas gel brands were included within the homecare and deodorant products. Page 1 was the cover page. The rest of the pages contained other categories, including both the store's own brands and national brands. The specific advertisement for each product included a picture of the product on offer; the brand name; the promotional technique and the price. While a comparison of the various pages in the store flyer is relatively easy, a cross-comparison of the flyers produced by different stores is not such an easy task for respondents. Given that the difficulty of the task is detrimental to the accuracy of the result (Huffman and Kahn, 1998), we proposed evaluating the different store flyer designs by undertaking a between-subject experiment. The between-subject design enabled us to determine whether different store flyer designs play a moderating role in the assessments that individuals make. Table 1 presents the four scenarios, defined in terms of three variables: (1) type of brand on cover page (national brand vs. store brand); (2) a slogan (e.g., "Better service, better deals") (presence or absence) and (3) \# of pages in the store flyer (8 vs. 20 pages). Respondents were randomly assigned to these four conditions.

Table 1. Between-subject manipulations made on store flyers

\begin{tabular}{|c|c|}
\hline \# Scenario & Profile \\
\hline $\mathbf{1}$ & National brand on cover page, not including slogan, flyer comprising 8 pages \\
\hline $\mathbf{2}$ & Store brand on cover page, not including slogan, flyer comprising 20 pages \\
\hline $\mathbf{3}$ & Store brand on cover page, including slogan, flyer comprising 8 pages \\
\hline $\mathbf{4}$ & National brand on cover page, including slogan, flyer comprising 20 pages \\
\hline
\end{tabular}

\footnotetext{
* More details about the paper are available from the authors upon request
} 
In a second step, a conjoint experiment was conducted. We propose a two-level factorial design in blocks of two, codified in a vector manner. The first step in designing a two-level experiment, in which all factors contain just two values $(+1,-1)$, establishes the number of possible profiles that can be built. Overall, a two-level full factorial design with $k$ factors will have $n=2^{\mathrm{k}}$ experiments with $C_{2}^{n}=\frac{n(n-1)}{2}$ possible pairs from which to form blocks.

The four designs for the four scenarios are shown in Table 2.

Table 2. Proposed design for the 1st scenario

\begin{tabular}{|c|c|c|c|c|c|c|c|}
\hline \multirow{2}{*}{ Block } & \multirow{2}{*}{ Profiles } & \multicolumn{3}{|c|}{ Main factors } & \multicolumn{3}{|c|}{ Two-factor interactions } \\
\hline & & F1 & F2 & F3 & F12 & F13 & F23 \\
\hline \multirow[t]{2}{*}{1} & 1 & -1 & -1 & -1 & 1 & 1 & 1 \\
\hline & 7 & -1 & 1 & 1 & -1 & -1 & 1 \\
\hline \multirow[t]{2}{*}{2} & 2 & $\overline{1}$ & $\overline{-1}$ & -1 & -1 & -1 & $\overline{1}$ \\
\hline & 5 & -1 & -1 & 1 & 1 & -1 & -1 \\
\hline \multirow[t]{2}{*}{3} & 5 & -1 & -1 & $\overline{1}$ & 1 & -1 & -1 \\
\hline & 8 & 1 & 1 & 1 & 1 & 1 & 1 \\
\hline \multicolumn{2}{|c|}{ Estimations obtained } & 2 & 2 & 2 & 2 & 2 & 2 \\
\hline
\end{tabular}

Proposed design for the 2nd scenario

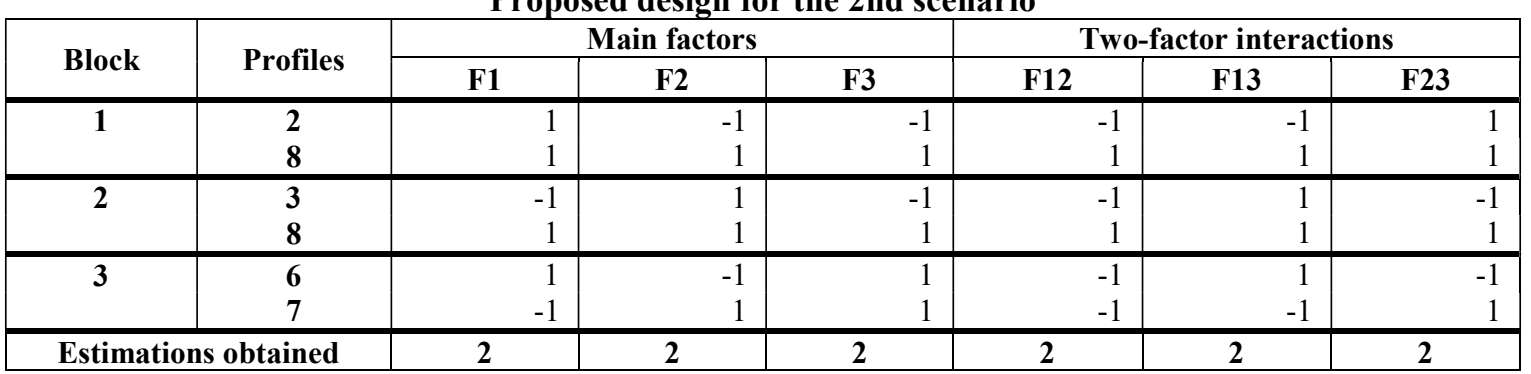

Proposed design for the 3rd scenario

\begin{tabular}{|c|c|c|c|c|c|c|c|}
\hline \multirow{2}{*}{ Block } & \multirow{2}{*}{ Profiles } & \multicolumn{3}{|c|}{ Main factors } & \multicolumn{3}{|c|}{ Two-factor interactions } \\
\hline & & F1 & F2 & F3 & F12 & F13 & F23 \\
\hline 1 & $\begin{array}{l}3 \\
5\end{array}$ & $\begin{array}{l}-1 \\
-1\end{array}$ & $\begin{array}{r}1 \\
-1\end{array}$ & $\begin{array}{r}-1 \\
1\end{array}$ & $\begin{array}{r}-1 \\
1\end{array}$ & $\begin{array}{r}1 \\
-1\end{array}$ & $\begin{array}{l}-1 \\
-1\end{array}$ \\
\hline 2 & $\begin{array}{l}4 \\
7\end{array}$ & $\begin{array}{r}1 \\
-1\end{array}$ & $\begin{array}{l}1 \\
1\end{array}$ & $\begin{array}{r}-1 \\
1\end{array}$ & $\begin{array}{r}1 \\
-1\end{array}$ & $\begin{array}{l}-1 \\
-1\end{array}$ & $\begin{array}{r}-1 \\
1\end{array}$ \\
\hline 3 & $\begin{array}{l}1 \\
4\end{array}$ & $\begin{array}{r}-1 \\
1 \\
\end{array}$ & $\begin{array}{r}-1 \\
1 \\
\end{array}$ & $\begin{array}{l}-1 \\
-1\end{array}$ & $\begin{array}{l}1 \\
1\end{array}$ & $\begin{array}{r}1 \\
-1\end{array}$ & $\begin{array}{r}1 \\
-1\end{array}$ \\
\hline Estima & btained & 2 & 2 & 2 & 2 & 2 & 2 \\
\hline
\end{tabular}

Proposed design for the $4^{\text {th }}$ scenario

\begin{tabular}{|c|c|c|c|c|c|c|c|}
\hline \multirow{2}{*}{ Block } & \multirow{2}{*}{ Profiles } & \multicolumn{3}{|c|}{ Main factors } & \multicolumn{3}{|c|}{ Two-factor interactions } \\
\hline & & F1 & F2 & F3 & F12 & F13 & F23 \\
\hline 1 & 4 & 1 & 1 & -1 & 1 & -1 & -1 \\
\hline 2 & 1 & -1 & -1 & -1 & 1 & 1 & 1 \\
\hline & 6 & 1 & -1 & 1 & -1 & 1 & -1 \\
\hline \multicolumn{2}{|c|}{ Estimations obtained } & 2 & 2 & 2 & 2 & 2 & 2 \\
\hline
\end{tabular}




\section{$\underline{\text { Tables }}$}

TABLE 1

Design obtained with a random design

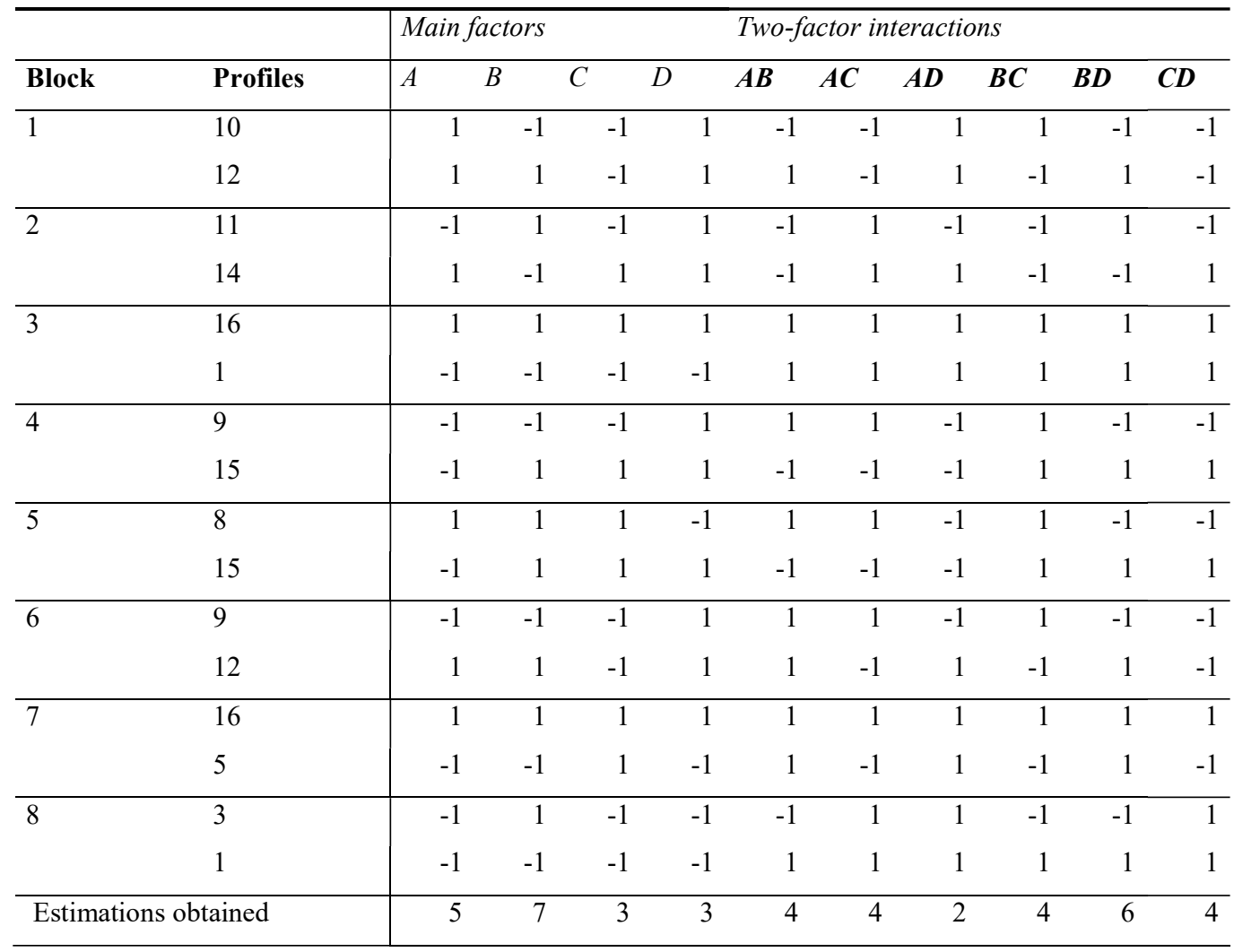

TABLE 2

Design obtained with the mirror image pairs

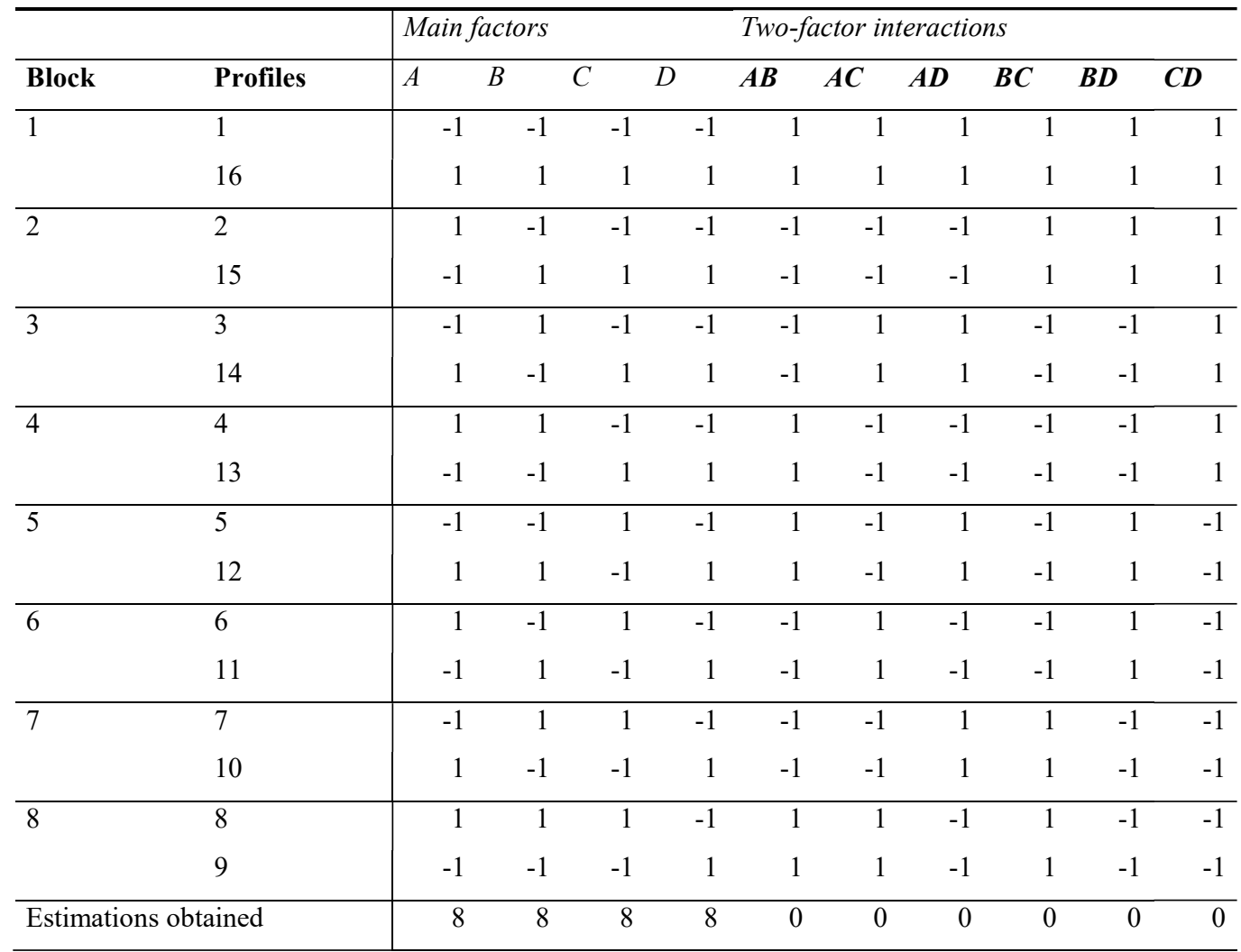


TABLE 3

Block Arrangements for a $2^{4}$ Design

\begin{tabular}{|c|c|c|c|c|}
\hline & Number & Bloc & Tarial & \\
\hline & & $B 1$ & $B 2$ & B3 \\
\hline 1 & 1 & A & $\mathrm{B}$ & $\mathrm{C}$ \\
\hline & 2 & A & B & D \\
\hline & 3 & A & $\mathrm{C}$ & $\mathrm{D}$ \\
\hline & 4 & B & C & D \\
\hline 2 & 5 & A & B & $\mathrm{CD}$ \\
\hline & 6 & A & $\mathrm{C}$ & BD \\
\hline & 7 & A & D & BC \\
\hline & 8 & B & $\mathrm{C}$ & $\mathrm{AD}$ \\
\hline & 9 & B & D & $\mathrm{AC}$ \\
\hline & 10 & $\mathrm{C}$ & D & $\mathrm{AB}$ \\
\hline 3 & 11 & A & $\mathrm{BD}$ & $\mathrm{CD}$ \\
\hline & 12 & B & $\mathrm{AD}$ & $\mathrm{CD}$ \\
\hline & 13 & $\mathrm{C}$ & $\mathrm{AD}$ & BD \\
\hline & 14 & D & $\mathrm{AC}$ & $\mathrm{BC}$ \\
\hline 4 & 15 & $\mathrm{AD}$ & $\mathrm{BD}$ & $\mathrm{CD}$ \\
\hline
\end{tabular}

TABLE 4

Design obtained with the block variables $A, B D$ and $C D$

\begin{tabular}{|c|c|c|c|c|c|c|c|c|c|c|c|c|c|}
\hline \multirow[b]{2}{*}{ Block } & \multirow[b]{2}{*}{ Profiles } & \multicolumn{5}{|c|}{ Main factors } & \multicolumn{7}{|c|}{ Two-factor interactions } \\
\hline & & $A$ & $B$ & & $\bar{C}$ & $D$ & $A B$ & $A C$ & $A D$ & $B C$ & $B D$ & & $C D$ \\
\hline \multirow[t]{2}{*}{1} & 1 & -1 & -1 & 1 & -1 & -1 & 1 & 1 & 1 & & 1 & 1 & 1 \\
\hline & 15 & -1 & & 1 & 1 & & -1 & -1 & -1 & & 1 & 1 & 1 \\
\hline \multirow[t]{2}{*}{2} & 2 & 1 & & 1 & -1 & -1 & $\overline{-1}$ & -1 & -1 & 1 & 1 & 1 & 1 \\
\hline & 16 & 1 & & 1 & 1 & 1 & 1 & 1 & 1 & & 1 & 1 & 1 \\
\hline \multirow[t]{2}{*}{3} & 3 & -1 & & 1 & -1 & -1 & -1 & 1 & 1 & -1 & 1 & -1 & 1 \\
\hline & 13 & -1 & -1 & 1 & 1 & 1 & 1 & -1 & -1 & -1 & 1 & -1 & 1 \\
\hline \multirow[t]{2}{*}{4} & 4 & 1 & & 1 & -1 & -1 & 1 & -1 & -1 & -1 & 1 & -1 & 1 \\
\hline & 14 & 1 & & 1 & 1 & 1 & -1 & 1 & 1 & -1 & 1 & -1 & 1 \\
\hline \multirow[t]{2}{*}{5} & 5 & -1 & -1 & 1 & 1 & -1 & 1 & -1 & 1 & -1 & 1 & 1 & -1 \\
\hline & 11 & -1 & & 1 & -1 & 1 & -1 & 1 & -1 & -1 & 1 & 1 & -1 \\
\hline \multirow[t]{2}{*}{6} & 6 & 1 & & 1 & 1 & $\overline{-1}$ & $\overline{-1}$ & 1 & -1 & -1 & 1 & 1 & -1 \\
\hline & 12 & 1 & & 1 & -1 & 1 & 1 & -1 & 1 & -1 & 1 & 1 & -1 \\
\hline \multirow[t]{2}{*}{7} & 7 & -1 & & 1 & 1 & -1 & $\overline{-1}$ & -1 & 1 & 1 & 1 & -1 & -1 \\
\hline & 9 & -1 & & -1 & -1 & 1 & 1 & 1 & -1 & 1 & 1 & -1 & -1 \\
\hline \multirow[t]{2}{*}{8} & 8 & 1 & & 1 & 1 & -1 & 1 & 1 & -1 & 1 & 1 & -1 & -1 \\
\hline & 10 & 1 & & -1 & -1 & & -1 & -1 & 1 & & 1 & -1 & -1 \\
\hline
\end{tabular}


TABLE 5

Design obtained with the block variables $\mathrm{B}, \mathrm{AD}$ and $\mathrm{CD}$

\begin{tabular}{|c|c|c|c|c|c|c|c|c|c|c|c|}
\hline \multirow[b]{2}{*}{ Block } & \multirow[b]{2}{*}{ Profiles } & \multicolumn{4}{|c|}{ Main factors } & \multicolumn{6}{|c|}{ Two-factor interactions } \\
\hline & & $A$ & $B$ & $C$ & $D$ & $A B$ & $A C$ & $A D$ & $B C$ & $B D$ & $C D$ \\
\hline \multirow[t]{2}{*}{1} & 1 & -1 & -1 & -1 & -1 & 1 & 1 & 1 & 1 & 1 & 1 \\
\hline & 14 & 1 & -1 & 1 & 1 & -1 & 1 & 1 & -1 & -1 & 1 \\
\hline \multirow[t]{2}{*}{2} & 2 & 1 & -1 & -1 & -1 & -1 & -1 & -1 & 1 & 1 & 1 \\
\hline & 13 & -1 & -1 & 1 & 1 & 1 & -1 & -1 & -1 & -1 & 1 \\
\hline \multirow[t]{2}{*}{3} & 3 & -1 & 1 & -1 & -1 & -1 & 1 & 1 & -1 & -1 & 1 \\
\hline & 16 & 1 & 1 & 1 & 1 & 1 & 1 & 1 & 1 & 1 & 1 \\
\hline \multirow[t]{2}{*}{4} & 4 & 1 & 1 & -1 & -1 & 1 & -1 & -1 & -1 & -1 & 1 \\
\hline & 15 & -1 & 1 & 1 & 1 & -1 & -1 & -1 & 1 & 1 & 1 \\
\hline \multirow[t]{2}{*}{5} & 5 & -1 & -1 & 1 & -1 & 1 & -1 & 1 & -1 & 1 & -1 \\
\hline & 10 & 1 & -1 & -1 & 1 & -1 & -1 & 1 & 1 & -1 & -1 \\
\hline \multirow[t]{2}{*}{6} & 6 & 1 & -1 & 1 & -1 & -1 & 1 & -1 & -1 & 1 & -1 \\
\hline & 9 & -1 & -1 & -1 & 1 & 1 & 1 & -1 & 1 & -1 & -1 \\
\hline \multirow[t]{2}{*}{7} & 7 & -1 & 1 & 1 & -1 & -1 & -1 & 1 & 1 & -1 & -1 \\
\hline & 12 & 1 & 1 & -1 & 1 & 1 & -1 & 1 & -1 & 1 & -1 \\
\hline \multirow[t]{2}{*}{8} & 8 & 1 & 1 & 1 & -1 & 1 & 1 & -1 & 1 & -1 & -1 \\
\hline & 11 & -1 & 1 & -1 & 1 & -1 & 1 & -1 & -1 & 1 & -1 \\
\hline
\end{tabular}

TABLE 6

Design obtained with the block variables $\mathrm{C}, \mathrm{AD}$ and $\mathrm{BD}$

\begin{tabular}{|c|c|c|c|c|c|c|c|c|c|c|c|}
\hline \multirow[b]{2}{*}{ Block } & \multirow[b]{2}{*}{ Profiles } & \multicolumn{4}{|c|}{ Main factors } & \multicolumn{6}{|c|}{ Two-factor interactions } \\
\hline & & $A$ & $B$ & $C$ & $D$ & $A B$ & $A C$ & $A D$ & $B C$ & $B D$ & $C D$ \\
\hline \multirow[t]{2}{*}{1} & 1 & -1 & -1 & -1 & -1 & 1 & 1 & 1 & 1 & 1 & 1 \\
\hline & 12 & 1 & 1 & -1 & 1 & 1 & -1 & 1 & -1 & 1 & -1 \\
\hline \multirow[t]{2}{*}{2} & 2 & 1 & -1 & -1 & -1 & -1 & -1 & -1 & 1 & 1 & 1 \\
\hline & 11 & -1 & 1 & -1 & 1 & -1 & 1 & -1 & -1 & 1 & -1 \\
\hline \multirow[t]{2}{*}{3} & 3 & -1 & 1 & -1 & -1 & -1 & 1 & 1 & -1 & -1 & 1 \\
\hline & 10 & 1 & -1 & -1 & 1 & -1 & -1 & 1 & 1 & -1 & -1 \\
\hline \multirow[t]{2}{*}{4} & 4 & 1 & 1 & -1 & -1 & 1 & -1 & -1 & -1 & -1 & 1 \\
\hline & 9 & -1 & -1 & -1 & 1 & 1 & 1 & -1 & 1 & -1 & -1 \\
\hline \multirow[t]{2}{*}{5} & 5 & -1 & -1 & 1 & -1 & 1 & -1 & 1 & -1 & 1 & -1 \\
\hline & 16 & 1 & 1 & 1 & 1 & 1 & 1 & 1 & 1 & 1 & 1 \\
\hline \multirow[t]{2}{*}{6} & 6 & 1 & -1 & 1 & -1 & -1 & 1 & -1 & -1 & 1 & -1 \\
\hline & 15 & -1 & 1 & 1 & 1 & -1 & -1 & -1 & 1 & 1 & 1 \\
\hline \multirow[t]{2}{*}{7} & 7 & -1 & 1 & 1 & -1 & -1 & -1 & 1 & 1 & -1 & -1 \\
\hline & 14 & 1 & -1 & 1 & 1 & -1 & 1 & 1 & -1 & -1 & 1 \\
\hline \multirow[t]{2}{*}{8} & 8 & 1 & 1 & 1 & -1 & 1 & 1 & -1 & 1 & -1 & -1 \\
\hline & 13 & -1 & -1 & 1 & 1 & 1 & -1 & -1 & -1 & -1 & 1 \\
\hline
\end{tabular}


TABLE 7

Estimations obtained by the three arrangements

\begin{tabular}{ll|lllllllllll}
\hline & & \multicolumn{7}{|l}{ Main factors } & \multicolumn{7}{l}{ Two-factor interactions } \\
\hline Block generator & Profiles & $A$ & $B$ & $C$ & $D$ & $\boldsymbol{A B}$ & $\boldsymbol{A C}$ & $\boldsymbol{A D}$ & $\boldsymbol{B C}$ & $\boldsymbol{B D}$ & $\boldsymbol{C D}$ \\
\hline $\mathrm{A}, \mathrm{BD}, \mathrm{CD}$ & 16 & 0 & 8 & 8 & 8 & 8 & 8 & 8 & 0 & 0 & 0 \\
$\mathrm{~B}, \mathrm{AD}, \mathrm{CD}$ & 16 & 8 & 0 & 8 & 8 & 8 & 0 & 0 & 8 & 8 & 0 \\
$\mathrm{C}, \mathrm{AD}, \mathrm{BD}$ & 16 & 8 & 8 & 0 & 8 & 0 & 8 & 0 & 8 & 0 & 8 \\
\hline Total & 48 & 16 & 16 & 16 & 24 & 16 & 16 & 8 & 16 & 8 & 8 \\
\hline
\end{tabular}

